\title{
Projeto de Extensão Pedagógica do Ilê Aiyê: uma proposta decolonial de educação ${ }^{1}$
}

\author{
Proyecto de Extensión Pedagógica del Ilê Aiyê: \\ una propuesta decolonial de educación
}

\author{
Ilê Aiyê Pedagogical Extension Project: \\ a decolonial education proposal
}

\section{Resumo}

Daniele Santos Santana ${ }^{2}$

\begin{abstract}
O presente estudo tem por objetivo investigar os projetos educacionais desenvolvidos pelo bloco afro Ilê Aiyê, tendo em vista sua importância na valorização da cultura afro-brasileira, a fim de destacar as principais atividades artístico-pedagógicas desenvolvidas pelo Bloco Carnavalesco para a promoção do debate sobre as questões étnico-raciais. Para tanto, faz-se uma pesquisa histórica da trajetória do bloco em questão, desde a sua criação, em 1974, na cidade de Salvador, Bahia, depois pela sua consolidação enquanto instituição de ensino formal com projetos de cunho pedagógico até o alcance dos Projetos de Extensão Pedagógica - fruto das ideologias ali defendidas, a saber: Banda Erê, Escola Mãe Hilda, Escola Profissionalizante e os Cadernos de Educação.
\end{abstract}

Palavras-Chave: Arte, Cultura Afro-brasileira, Educação, Ilê Aiyê.

\section{Resumen}

El presente estudio tiene por objetivo investigar los proyectos educativos desarrollados por el grupo afro Ilê Aiyê, teniendo en vista su importancia en la valorización de la cultura afro-brasileña, a fin de destacar las principales actividades artístico-pedagógicas desarrolladas por el grupo para la promoción del debate sobre las cuestiones étnico-raciales. Para ello, se hace una investigación histórica de la trayectoria del grupo en cuestión, desde su creación, en 1974, en la ciudad de Salvador, Bahia, después por su consolidación como institución de enseñanza formal con proyectos de cuño pedagógico hasta el alcance de los Proyectos de Extensión Pedagógica fruto de las ideologías allí defendidas, a saber: Banda Erê, Escuela Madre Hilda, Escuela Profesional y los Cuadernos de Educación.

Palabras Clave: Art, Cultura afro-brasileña, Educación, Ilê Aiyê.

\begin{abstract}
The present study aims to investigate the educational projects developed by the Afro-Brazilian group Ilê Aiyê, in view of its importance in enhancing Afro-Brazilian culture, in order to highlight the main artistic and pedagogical activities developed by the musician group to promote debate on ethnic-racial issues. In order to do so, it is a historical research of the trajectory of the Ilê, since its creation, in 1974, in the city of Salvador, Bahia, later for its consolidation as a formal teaching institution with pedagogical projects until reaching the Projects of Pedagogical Extension - fruit of the ideologies defended there, namely: Banda Erê, Escola Mãe Hilda, Vocational School and the Cadernos de Educação.
\end{abstract}

Keywords: Art, Afro-Brazilian Culture, Education, Ilê Aiyê.

\footnotetext{
${ }^{1}$ Artigo apresentado no Simpósio Temático 08 (Práticas e Políticas Educacionais na América Latina) durante o II Seminário Latino-Americano de Estudos em Cultura - SEMLACult em Foz do Iguaçu/PR, Brasil, 2018.

${ }^{2}$ Mestra em Arte; Universidade de Brasília - UnB; Brasília, Distrito Federal, Brasil; dany.zunder@ gmail.com.
} 


\section{Introdução}

Um longo capítulo da história do Brasil é composto pela luta e resistência dos povos que aqui se transformaram em mão de obra escrava e passaram por um processo de aculturação. Em especial, destacam-se os primeiros habitantes da "Terra Brasilis" e aquele/as que para cá foram trazido/as de modo arbitrário: os povos indígenas e o/as africano/as, respectivamente.

Movimentos e lideranças sociais, universidades, centros religiosos, figuras e partidos políticos, dentre outro/as, foram responsáveis por implementar mudanças significativas no que tange aos direitos desses grupos, principais representantes das culturas tradicionais do país.

No que se refere ao campo pedagógico, a criação da Lei de Diretrizes e Bases da Educação (LDBEN) de 1996 - Lei n. 9.394/1996, em um ato de reconhecimento a estas lutas, especificou as três matrizes que deveriam ser abarcadas no ensino da História do Brasil: indígena, africana e europeia, ratificando, assim, a Carta Magna de 1988, que apontava que "o ensino da História do Brasil levará em conta as contribuições das diferentes culturas e etnias para a formação do povo brasileiro" (BRASIL, 1988).

Antes mesmo destas determinações legais aparecerem, vários grupos já se identificavam com os dos ideais propostos por estas mudanças e enquanto símbolo de resistência cultural negra, como em 1974, no bairro do Curuzu, na cidade de Salvador, Bahia, quando surgiu um grupo musical que já objetivava "preservar, valorizar e expandir a cultura afro-brasileira, homenageando países africanos e revoltas negras brasileiras que contribuíram fortemente para o processo de identidade étnica e autoestima do negro" (ILÊE AIYÊ, 2016). A ideia inicial era batizar o grupo de "Poder Negro" devido à influência dos grupos norteamericanos que lutavam pelo fim da separação racial. Entretanto, para evitar problemas com as autoridades, os integrantes resolveram dar o nome Ilê Aiyê, que significa "Casa do Barro Preto", como afirma a pesquisadora carioca em Cultura e Comunicação, Ângela Schaun (2001),

Ilê Aiyê quer dizer A Casa do Barro Preto na língua nagô, o abrigo do homem preto. O nome ia ser Poder Negro, conforme relata a Yalorixá Mãe Hilda de Jitolou, mãe de santo do Terreiro de Jitolou, no Curuzu, onde está a sede do Ilê. Mãe Hilda relembra que O Ilê Aiyê inicia o seu projeto educacional a partir dos anos 70, mais precisamente em 10 de novembro de 1974, baseado na comunicação da cultura negra enquanto estética própria inspirada na raiz africana, através do resgate dos principais arquétipos da ancestralidade religiosa. 
Atualmente, o local destinado aos ensaios do Ilê Aiyê e que abriga a Escola Mãe Hilda (escola primária mantida pelo bloco afro, que leva o este nome em homenagem à Ialorixá do Terreiro Jitolu e matriarca do Ilê), recebeu o nome de Senzala do Barro Preto, remetendo-nos ao alojamento que, nas antigas fazendas ou casas senhoriais, abrigava as pessoas escravizadas da época.

Conhecida dos livros de história e da memória das pessoas escravizadas no Brasil, a senzala sempre foi sinônimo de sofrimento, pois remete aos descasos sofridos pelo/as negro/as de então e à maneira desumana como foram tratado/as. Em uma abordagem contrária (inclusive as de alguns movimentos ligados à questão do/a negro/a no Brasil, que preferem o termo "quilombo", quando se tratando de exemplo de resistência), o Ilê Aiyê denota que foi na senzala, assim como nos quilombos, terreiros e outros espaços, que a cultura africana encontrou força para (re) existir, pois ali também que o/as negro/as escravizado/as aprendiam o quanto podiam sobre sua própria cultura, costumes e crenças. E é justamente esta a significação que a Senzala do Barro Preto (FIG.1) pretende passar à comunidade em que atua, pois, como aponta uma das frases mais emblemáticas da luta de classes atualmente utilizada nas redes sociais: "a casa grande surta quando a senzala aprende a ler". E é na Senzala que o/as jovens da comunidade do Curuzu e adjacências têm suas oportunidades de aprender, seja através da educação formal, com a escola primária, seja nas demais formas de aprendizado, com oficinas e cursos variados oferecidos no local.

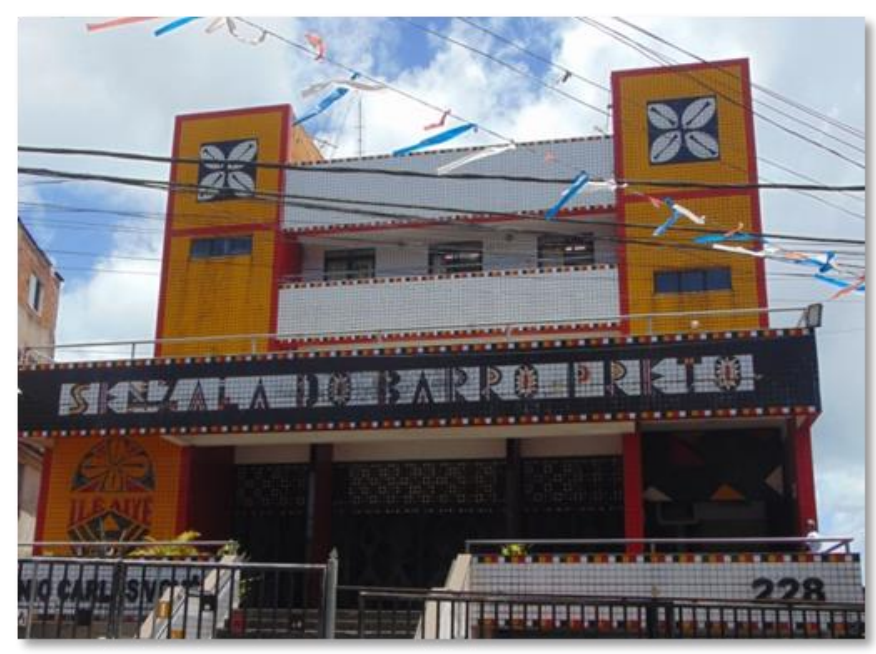

Figura 1 - Senzala do Barro Preto

Fonte: Acervo Pessoal (2017)

Outros grupos de Salvador, tais como o Olodum, o Ara Ketu e o Pracatum, também trazem uma clara preocupação com a educação, a comunicação e a cultura negras, no sentido 
de incluir um novo padrão estético e, portanto, também ético e político, destacando, para tanto a cultura afro-brasileira. Em meio a esta gama de possibilidades, a eleição do grupo Ilê Aiyê deve-se por sua iniciativa primordial, pois se trata de um dos primeiros blocos de Salvador a desenvolver tais projetos, e por ser um bloco que fez e continua fazendo parte da formação cultural, política, artística e cidadã da comunidade que o cerca e desta pesquisadora.

Considerando que aprender a valorizar sua própria cultura é um dos primeiros passos para respeitar e expandir sua identidade fortalecida, partindo da percepção coletiva para a individual, ou seja, é ter sua identidade pessoal representada por um grupo de referência, a concepção identitária proposta pelo Ilê Aiyê, por fazer uso de elementos da cultura africana, de modo a emancipar e demonstrar a beleza que, por vezes, foi ofuscada pela cultura hegemônica, reflete a proposta decolonial de educação e cultura. Neste sentido, aproxima-se desta perspectiva por estudar e difundir um pensamento crítico do ponto de vista dos "marginalizados" pela sociedade capitalista e propondo uma tendência educacional distante das amarras eurocêntricas.

Com base no exposto e observando os pressupostos da educação promovida pelo Ilê Aiyê, infere-se que as atividades artístico-pedagógicas por eles propostas enfatizam ainda mais a necessidade de uma abordagem antropológica e cultural afrocentrada. Esta que, por sua vez, se traduz em um tipo de pensamento em que o/as africano/as são visto/as como sujeitos e agentes que atuam sobre sua imagem cultural e de acordo com seus interesses humanos, contrapondo, assim, o entendimento de que "toda a produção que não atende aos interesses eurocêntricos é marginalizada", como já nos alertava o professor de Estudos AfroAmericanos, Molefi Kete Asante (2009).

A identificação do indivíduo com sua cultura primária consolida uma autoestima acentuada - valorização esta evidenciada no trabalho do Ilê desde sua ação pedagógica (com abordagens que enfatizam a história, os personagens e as lutas dos povos africanos), o figurino utilizado pelos integrantes do grupo, a dança apresentada pelos integrantes da Banda Erê e, claro, pelas letras das músicas entoadas pelo grupo e que se constituíram como verdadeiros hinos de amor e orgulho ao pertencimento da cultura deixada como legado pelos africanos.

\section{Projetos de Extensão Pedagógica do Ilê Aiyê e sua proposta Decolonial}

A partir da identificação, apropriação e disseminação dos símbolos mais fortes da cultura africana (música, dança, vestuário, etc.) é que os objetivos mais visíveis dos trabalhos 
pedagógicos e culturais do Ilê Aiyê são concretizados. Conforme descrição em documento referencial do grupo, destinado a fundamentar suas ações, observa-se como essa valorização toma forma, conforme o que se segue:

Propondo seu trabalho político-pedagógico consciente, o Ilê o faz através da seleção da temática, da dança e de códigos de linguagem, que permeia a transmissão da ancestralidade africana com o contexto histórico-social do negro em condição de escravo no Brasil, com o cotidiano presente do negro baiano, além de trabalhar o caráter universal da questão negra (ILÊ AIYÊ, 1996, p. 24).

Alguns autores, como, por exemplo, o jornalista e sociólogo Muniz Sodré (1988), já alertavam sobre a relevância de estudar a cultura brasileira através das suas variadas matrizes, sem o foco único na hegemonia europeia.

\begin{abstract}
A ideia moderna de cultura, que ganha força com o progresso do capitalismo e, em nome do qual, a Europa inflige a África, durante três séculos e meio, o genocídio de milhões de pessoas. O capitalismo, o progresso, a civilização, a cultura ocidental se tornam possíveis a partir do tráfico de escravos, da grande diáspora negra. [...] Isso se encontra a sua legitimidade nos imperativos da Verdade produzida pela cultura, "invenção" exportada da Europa no final do século XVIII. Desde então esta palavra [cultura] tem estado no centro de projetos, obras, ciências, tal é o poder da crença que nela deposita (SODRÉ, 1988, p. 42).
\end{abstract}

Assim, parte-se da percepção de uma cultura que foi imposta e que é incessantemente ensinada nas escolas, de modo a homogeneizar os costumes da maioria das comunidades em nome dos saberes europeus e que precisa ser dessacralizada. Tal domínio cultural vem de séculos de exploração e aculturação promovido pelos países que colonizaram a América e a África, que fizeram uso, entre outras formas, do ensino formal a favor dos seus interesses. Um exemplo clássico é a Academia de Belas-Artes, a primeira instituição oficial destinada ao ensino da Arte, que já surgiu atendendo aos interesses da coroa, uma vez que "estivera a serviço do adorno do Reinado e do Império, e com o dirigismo característico do espírito neoclássico de que estava impregnada, servira à conservação do poder" (BARBOSA, 2010, p. 17).

Esta vertente de ensino que direciona para a massificação da cultura hegemônica e que, é repetida por séculos na história brasileira. Neste sentido, Duarte Júnior (1996, p. 70) aponta para a necessidade de reconhecimento de uma cultura e história próprias, conforme se segue:

Conhecendo a arte do meu tempo e cultura, adquiro fundamentos que me permitem uma concomitante compreensão do sentido da vida que é vivida aqui e agora. E mais: conhecendo a arte pretérita da cultura onde vivo posso vir a compreender as transformações operadas no seu modo de sentir e entender a vida ao longo da história até meus dias. 
De encontro à apropriação exagerada da cultura europeia, o Ilê Aiyê desenvolve atividades influenciadas por outro meio cultural, conforme aponta Schaun (2001):

O Ilê Inspirou-se em referências teóricas para sua idealização, reportando-se a um modelo de ideologização política a partir das informações do movimento negro norteamericano da década de 1970, das lutas de independência dos países africanos e, sobretudo, na resistência cultural afro-brasileira originária do Candomblé.

Este caminho seguido pelos projetos do Ilê Aiyê refletem uma visão decolonial de educação, tendo em vista que a decolonização é uma resposta epistêmica ao colonialismo, que envolve diversas esferas (do ser, do saber e de poder). e que

O processo de decolonização não deve ser confundido com a rejeição da criação humana realizada pelo Norte global e associado com aquilo que seria genuinamente criado no Sul, no que pese práticas, experiências, pensamentos, conceitos e teorias. [...] Nesse sentido, é revelador que ao esforço de teorização no Brasil e na América Latina caibam os rótulos de "pensamento" e não "teoria" social e política. Atualmente, diversos autores e autoras, situados tanto nos centros quanto nas periferias da produção da geopolítica do conhecimento, questionam o universalismo etnocêntrico, o eurocentrismo teórico, o nacionalismo metodológico, o positivismo epistemológico e o neoliberalismo científico contidos no mainstream das ciências sociais. (BALLESTRINI, 2013, p. 109)

Coincidentemente, apesar de não ser uma ligação oficial a estes conceitos, mas fazendo analogia aos mesmos, foi concebido o Projeto de Extensão Pedagógica (PEP), que tem como objetivo "sistematizar e socializar as práticas e produções educativas do Ilê Aiyê e editar os cadernos de Educação. O PEP coordena as três escolas do Ilê: Mãe Hilda, Escola de Percussão Banda Erê e a Escola Profissionalizante" (ILÊ AIYÊ, 2006, p. 03).

A Escola Mãe Hilda, criada em 1995 inicialmente para auxiliar as crianças que tinham dificuldades de aprendizado na escola, consolidou a vertente educacional formal do Ilê, atendendo estudantes das séries iniciais do ensino fundamental. Para analisar os objetivos básicos da Escola, os pontos fundamentais do seu trabalho pedagógico estão descritos no documento referencial do grupo, conforme se segue:

1. Resgate dos saberes cotidianos locais;

2. Valorização das experiências vivenciadas anteriormente pelos alunos;

3. Utilização de atividades como desenvolvimento de oficinas, vivências e textos envolvendo métodos étnicos que auxiliem novas formas de produzir conhecimentos;

4. Construção de elos educativos que permitam um diálogo entre as várias áreas do conhecimento;

5. Relação horizontal professor/aluno, privilegiando a proximidade e afetividade, respeitadas as idiossincrasias e identidade dos atores envolvidos no processo (ILÊE AIYÊ, 2016). 
A Banda Erê, por sua vez, é um projeto artístico-pedagógico que tem como foco o ensino da música. Fundada em 1992, promove aulas de percussão a jovens do bairro que abriga a Associação - Liberdade - e arredores. Três anos após sua fundação, passa a oferecer também classes que contemplam temas como cidadania, história, literatura, saúde corporal, dança, canto e coral (ILÊ AIYÊ, 2016).

Numa perspectiva voltada diretamente para o mercado de trabalho, em 1997, a Escola Profissionalizante do Ilê Aiyê deu início às atividades de ensino que tinham como objetivo a auto sustentação do/as jovens. Concomitante com as aulas de língua portuguesa e matemática, o/as estudantes são capacitado/as em cursos que variavam desde estética afro à eletricidade predial.

Outro componente importante do Projeto de Extensão Pedagógica do Ilê Aiyê, os Cadernos de Educação foram produzidos desde o primeiro ano dos projetos, em 1995. Criados com o intuito de levar aos mais diversos tipos de leitore/as textos informativos de grande importância histórica e pedagógica, se consolidaram como instrumentos fundamentais para o estudo da histórica africana e afro-brasileira, indo ao encontro das propostas apresentadas pela Lei 10.639/03, que instituiu o ensino da história e cultura de origem africana na educação básica. É de suma importância também enfatizar que os Cadernos de Educação, em geral, contam o tema do carnaval do Ilê Aiyê no referido ano, salvo poucas exceções. Em resumo, o conteúdo dos Cadernos apresenta uma riqueza de temas, imagens e símbolos relacionados à cultura afro, bem como auxilia na abordagem, em sala de aula, de temas correlatos. Por meio deles, as crianças têm contato com os temas propostos para o Carnaval, bem como as músicas serão utilizadas naquele ano. Essas referências podem ser facilmente percebidas nos títulos dos Cadernos de Educação que reforçam o contexto apresentado, como os exemplos abaixo:

Volume I: Organização e Resistência Negra (S/D)

Volume II: Civilização Bantu (S/D)

Volume III: Zumbi 300 anos - Ilê Aiyê 21 anos (1996)

Volume V: Pérolas Negras do Saber (S/D)

Volume VII: Revolta de Búzios (1991)

Volume X: Malês e a Revolução (2002)

Volume XII: Mãe Hilda Jitolu - guardiã da fé e da tradição africana (2009 / 2 ${ }^{\mathrm{a}}$ Edição) (FIG. 2). 


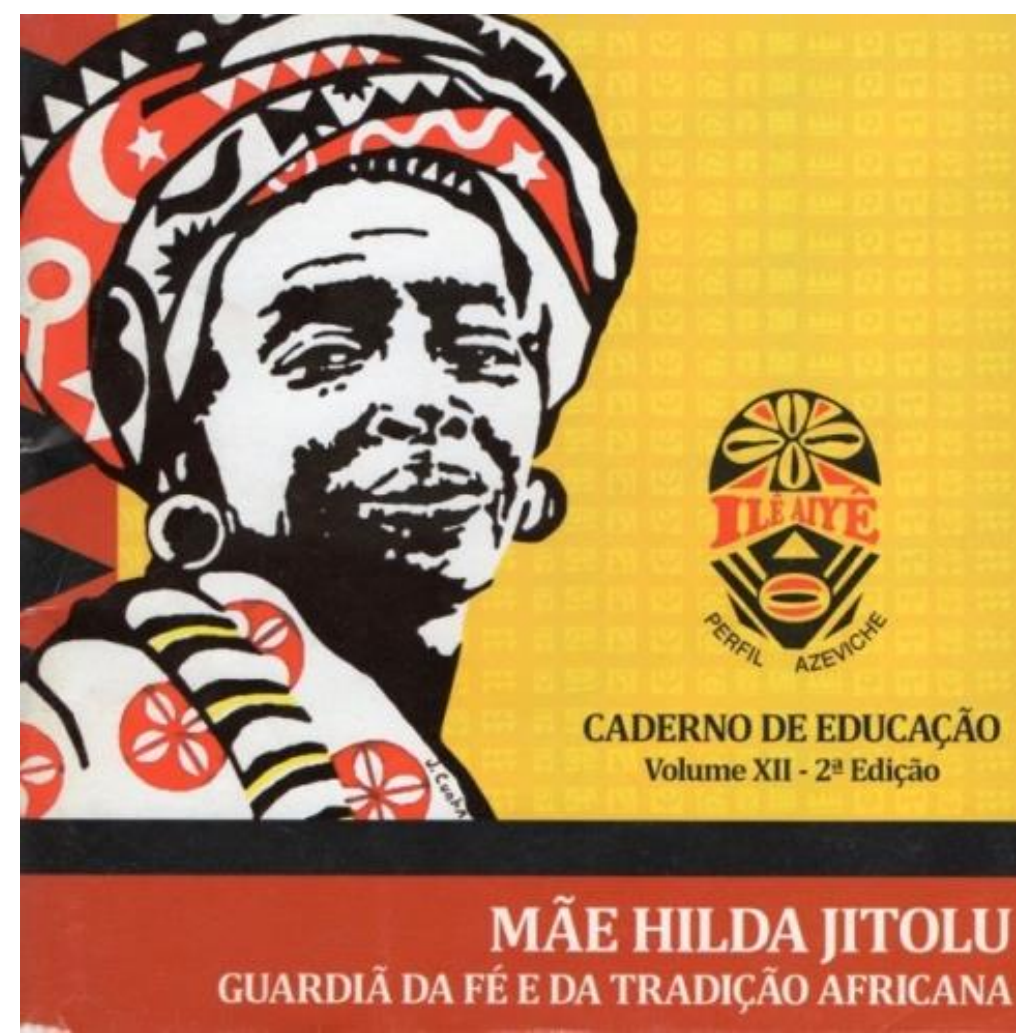

Figura 3 - Capa do Caderno de Educação do Ilê Aiyê vol. XII Fonte: Acervo Pessoal (2017)

Os títulos acima descritos e os objetivos educacionais do PEP nos fazem perceber qual a versão da história enfatizada pela proposta pedagógica do Ilê. Temas, personalidade, mitos, fatos históricos e outros itens que partem de uma perspectiva afrocentrada e de uma proposta decolonial de educação, uma vez que os saberes já existentes não são aniquilados, mas sim somados a uma nova visão dos fatos. É como reescrever a história do/a negro/a no Brasil a partir de outros olhares, em especial do africano e afro-brasileiro.

\section{Referências}

BRASIL. Lei n. 9.394, de 20 de dezembro de 1996. Estabelece as diretrizes e bases da educação nacional. Brasília, 1996. Disponível em: <http://www.planalto.gov.br/ccivil_03/leis/L9394.htm>. Acesso em 1º maio 2016.

Lei n. 10.639, de 9 de janeiro de 2003. Altera a Lei n. 9.394, de 20 de dezembro de 1996, que estabelece as diretrizes e bases da educação nacional, para incluir no currículo oficial da Rede de Ensino a obrigatoriedade da temática "História e Cultura Afro-Brasileira", e dá outras providências. Brasília, 2003. Disponível em: <http://www.planalto.gov.br/ccivil_03/leis/2003/L10.639.htm>. Acesso em 1º maio 2016. 
Lei n. 11.645, de 10 de março de 2008. Altera a Lei n. 9.394, de 20 de dezembro de 1996, modificada pela Lei n. 10.639, de 9 de janeiro de 2003, que estabelece as diretrizes e bases da educação nacional, para incluir no currículo oficial da rede de ensino a obrigatoriedade da temática "História e Cultura Afro-Brasileira e Indígena". Brasília, 2008. Disponível em: <http://www.planalto.gov.br/ccivil_03/_ato2007-2010/2008/lei/111645.htm>. Acesso em $1^{\circ}$ maio 2016.

ILÊ AIYÊ. Salvador, 2016. Disponível em: <http://www.ileaiyeoficial.com/>. Acesso em: $1^{\text {o }}$ maio 2016.

SCHAUN, Ângela. EDUCOMUNICAÇÃO: Ilê Aiyê e a Visibilidade da Cidadania Negra. In: XXIV Congresso Brasileiro de Ciências da Comunicação, Campo Grande, 2001. Disponível em: <http://www.usp.br/nce/wcp/arq/textos/57.pdf>. Acesso em: $1^{\circ}$ maio 2016.

\section{Bibliografia consultada:}

ASANTE, Molefi Kete. Afrocentricidade: notas sobre uma posição disciplinar. In: NASCIMENTO, Elisa Larkin (Org.). Afrocentricidade: uma abordagem epistemológica inovadora. São Paulo: Selo Negro, 2009. (Sankofa: matrizes africanas da cultura brasileira vol. 4).

BALLESTRIN, Luciana. “América Latina e o giro decolonial”. Revista Brasileira de Ciência Política, n. 11, Brasília, maio-agosto de 2013, PP. 88-117.

BARBOSA, Ana Mae. Arte-Educação no Brasil. São Paulo: Perspectiva, 2010.

CADERNO DE EDUCAÇÃO DO ILÊ AIYÊ. O negro e o poder. Vol. XIV. Projeto de Extensão Pedagógica. Salvador: EGBA, 2006.

DUARTE JÚNIOR, João Francisco. Por que Arte-Educação? São Paulo: Papirus, 1996. FERRAZ, Maria Eloísa C. de T. \& FUSARI, Maria F. de Rezende e. Metodologia do Ensino da Arte. São Paulo: Cortez, 1993.

MOREIRA, Anália de Jesus. As concepções de corpo na associação bloco Carnavalesco Ilê Aiyê: um estudo a partir da história do Bloco e das práticas pedagógicas das escolas Banda Erê e Mâe Hilda. 2013. 138 p. Tese (Doutorado em Educação) - Programa de Pós-Graduação e Educação, Universidade Federal da Bahia, Salvador, 2013. Disponível em: $<$ https://repositorio.ufba.br/ri/bitstream/ri/13621/1/TESE\%20DE\%20ANALIA\%20DE\%20JE SUS\%20MOREIRA.pdf>. Acesso em: 25 abr. 2016.

SODRÉ, Muniz. O terreiro e a cidade: a forma social negro-brasileira. Petrópolis, RJ: Vozes, 1988. 